TuberCulosis (TBC) is characterized by a complex immune response which parallels the clinical course of the disease. In this respect, acquired resistance, delayed hypersensitivity reaction and anergy are the main types of immune reactivity to mycobacterial antigens. In view of the presence of nonspecific and specific immune deficits in TBC patients, a clinical trial was carried out in a group of 20 individuals with active pulmonary TBC by oral administration of acetyl-L-carnitine (ALC). This drug, which has been shown to possess immunomodulating activities, was able to upregulate the $T$-dependent antibacterial activity in TBC patients after 30 days' treatment, while the same activity decreased in patients receiving placebo only. On the other hand, ALC did not modify serum levels of tumour necrosis factor- $\alpha$, in the same individuals. This cytokine plays a detrimental rather than beneficial role in TBC pathogenesis. In the light of these data, ALC seems to be a powerful immunomodulator in the course of Mycobacterium tuberculosis infection and other mycobacteriosis.

Key words: Acetyl-I-carnitine, Immune response, Lymphocytes, Macrophages, Tuberculosis, Tumour necrosis factor- $\alpha$

\section{Immunological responses in patients with tuberculosis and in vivo effects of acetyl-L-carnitine oral administration}

\section{Emilio Jirillo, ${ }^{1, C A}$ Maria Altamura, ${ }^{1}$ Carlo Marcuccio, ${ }^{1}$ Cosimo Tortorella, ${ }^{2}$ Claudio De Simone ${ }^{3}$ and Salvatore Antonaci ${ }^{2}$}

\author{
${ }^{1}$ Immunologia and ${ }^{2}$ Medicina Interna, Medical \\ School, University of Bari, Bari, Italy; \\ ${ }^{3}$ Malattie Infettive, Medical School, Úniversity of \\ L'Aquila degli Abruzzi, L'Aquila, Italy
}

${ }^{\mathrm{CA}}$ Corresponding Author

\section{Introduction}

Tuberculosis (TBC) is a pathological process characterized by a broad spectrum of immunological responses which correlate with the clinical course of the disease. ${ }^{1-3}$ In TBC, immune responsiveness depends on three basic mechanisms: (1) acquired cellular resistance; (2) delayed type hypersensitivity (DTH); and (3) anergy. ${ }^{13}$

Acquired cellular resistance is a protective mechanism in which specific $\mathrm{T}$-cells are activated by macrophages, the so-called antigen presenting cells. ${ }^{4}$ With special reference to mycobacterial antigens, mainly proteins, e.g. heat shock proteins (HSP), are presented by macrophages to both human and murine $\gamma \delta^{+}$cells. $^{58}$ On the other hand, murine $\mathrm{CD}^{+}$and $\mathrm{CD}^{+}$cells seem to participate to acquired resistance, ${ }^{9}$ even if others claim that only $\mathrm{CD}^{+}$cells are the major protective subset in long-term protective studies. ${ }^{10}$ In humans, recent studies have pointed out that $\mathrm{CD}^{+}$cells kill monocytes which contain mycobacteria regardless of the T-helper $(\mathrm{h})_{1}-\mathrm{Th}_{2}$ subset distinction and of the HSP recognition. ${ }^{11}$

D'TH is a detrimental reaction dependent on the sensitization of specific lymphocytes by mycobacterial antigens and usually leads to granuloma formation. ${ }^{13}$ Granuloma, which consists of an accumulation of macrophages, may undergo either a protective evolution with microorganism neutralization or a caseification with tissue damage. ${ }^{1-3}$
In the phase of macrophage accumulation, two inflammatory cytokines (CKs), namely the monocyte chemotactic protein-1 (MCP-1) and the macrophage inhibiting factor play an important role. $^{1-3}$ In the phase of tubercular granuloma evolution interferon- $\gamma$ (IFN- $\gamma$ ) and interleukin-2 (IL-2) are protective, ${ }^{12,13}$ while tumour necrosis factor- $\alpha(\mathrm{TNF} \alpha)$ is mostly involved in granuloma destruction. $^{14}$

With special reference to $T N F \alpha$, it has been reported that lipoarabinomannan (LAM) from the $M$. tuberculosis cell wall is responsible for the production of this $\mathrm{CK},{ }^{15}$ as is also confirmed by studies on LAM-induced transcription of mRNA for several CKs, even including TNF $\alpha .{ }^{16}$ Furthermore, by analogy with other intracellular infections (e.g. M. avium and M. bovis infections, listerosis, toxoplasmosis and trypanosomiasis ${ }^{17} \mathrm{TNF} \alpha$ should also play a protective role in the case of $M$. tuberculosis infection. However, according to Filley and Rook $^{18}$ virulent TBC strains produce a factor which alters the normal function of $T N F \alpha$, rendering it toxic to host tissue. Therefore, many clinical and laboratory findings in TBC patients may be ascribed to $\mathrm{TNF} \alpha$ release, such as fever, weight loss, necrosis, intravascular coagulation and acute phase protein release. ${ }^{19}$ On the other hand, data of Barnes et al. ${ }^{20}$ support a protective role for TNF $\alpha$ in the course of pleuritis, which usually resolves in the absence of therapy. Moreover, Takashima et al. ${ }^{21}$ report a reduction of $\mathrm{TNF} \alpha$ in patients with chronic 
TBC. Taken together, these findings attribute a noxious role to TNF $\alpha$ in the course of TBC, while beneficial effects of this $\mathrm{CK}$ may arise when it is moderately produced or locally released as in the case of pleural effusion.

Anergy is a clinical condition of depressed immune function, as observed in patients with advanced refractory TBC. ${ }^{1-3}$ Several mechanisms have been postulated for explaining the immunosuppression in TBC patients. In this respect, bacterial cell wall components, e.g. D-arabino-Dgalactan, can downregulate $\mathrm{Fc}$ receptor $(\mathrm{R})$ function on cell membranes by circulating in the form of immunocomplexes. ${ }^{22}$ Furthermore, prostaglandin $\mathrm{E}_{2}$ release by monocytes may reduce IL-2 production and decrease expression of IL-2 R. ${ }^{23}$ Another immunosuppressive agent is represented by IL-1, which inhibits T-lymphocyte proliferation by protein purified derivative (PPD) when produced in exaggerated amounts. ${ }^{24}$ Finally, a $25 \mathrm{kDa}$ glycoprotein derived from $M$. tuberculosis has been shown to inhibit phagocytic functions. ${ }^{25}$

These data emphasize that a plethora of suppressive factors may be involved in the depression of immune response in TBC patients and their recognition is important for the establishment of therapeutic strategies.

\section{Monitoring of the Immune Status in Patients with TBC}

Until now, many studies have been focused on T-lymphocyte functions in TBC individuals and, in particular, $\mathrm{T}$-cell response to mitogens and antigens has been evaluated. In contrast, less information is available on polymorphonuclear cell (PMN) and monocyte functions, and on B-cell activity.

In a recent study, a group of 14 patients with TBC (seven individuals with acute disease and seven individuals with chronic disease) have been evaluated in terms of phagocytic and B-cell functions. ${ }^{26}$ PMN and monocyte activities were assessed by determining their chemotactic capacity and ability to phagocytose Candida albicans. At the same time, the release of two inflammatory CKs, leucocyte inhibiting factor (LIF) and MCP-1 was determined Results show that chemotaxis, phagocytosis and killing were reduced regardless of the disease status. ${ }^{26}$ The impaired release of LIF and MCP-1 could also explain the altered phagocytic activity.

Assessment of B-cell responsiveness was performed by evaluating in vitro antibody synthesis in a plaque-forming cell system, using pokeweed mitogen (PWM) as a polyclonal activator and PPD as a specific antigen. In patients with acute $\mathrm{TBC}$, anti-PPD antibody response was significantly augmented, while in patients with acute and chronic
TBC PWM-induced antibody production fell within normal values. ${ }^{26}$ These last results are in accordance with findings of others who detected elevated IgG serum levels to PPD in acute TBC. ${ }^{27}$ Moreover, a strict correlation was found between ELISA positivity for anti-PPD IgG antibody and TBC diagnosis. ${ }^{28}$ In chronic patients the lack of anti-PPD antibody response may depend on B-cell immunosuppression, despite an elevated frequency of B-cells.

The bulk of the above data support the usefulness of monitoring different compartments of the immune system in TBC patients, since deficits in these individuals seem to be more vast than expected.

\section{Oral Administration of Acetyl-L-carnitine in Patients with Active Pulmonary Tuberculosis}

Much evidence supports the concept that the immune response plays an important role in the pathogenesis of TBC. Quite interestingly, the authors' previous results emphasize that even patients in the acute phase exhibit multiple deficits of either nonspecific or specific immunity. Now, the question arises concerning the opportunity to immunomodulate these subjects in order to avoid superimposition of other infections (e.g. historically, measles; nowadays, HIV infection). However, the risk exists that classical biological response modifiers (BRM), which enhance immune response via $C K$ release, ${ }^{29}$ may trigger detrimental $\mathrm{DHR}$ for the host. In this framework, it was reasoned that a putative BRM, which may increase the metabolic performance of immune cells rather than inducing release of noxious mediators, should be more appropriate for treating TBC subjects.

Just recently, ALC, a substance which is actively involved in either the transport and oxidation of fatty acids into mitochondria, or in the production and incorporation of their unsaturated forms into membrane phospholipids, ${ }^{30}$ has been shown to possess immunoregulatory properties. Studies in this direction have, in fact, demonstrated, that ALC reduced macrophage and lymphocyte function decline in aged rats ${ }^{31}$ and enhanced mitogen-induced lymphocyte proliferation in the elderly. ${ }^{32}$ In AIDS subjects treated with ALC an improvement of immunocompetence was found ${ }^{33}$ and this correlates with the reduced levels of carnitine detected in these patients. $^{34}$

On this basis, 20 subjects with active pulmonary TBC were enrolled in a double blind, randomized, controlled parallel study. ${ }^{35}$ Ten patients were treated orally with $2 \mathrm{~g}$ ALC/day (Nicetile, SigmaTau, Pomezia, Italy) for 30 days. The control group received placebo only. Two main immune para- 
meters were followed up at day 0 and day 30, namely the antibacterial activity and TNF $\alpha$ serum levels.

Antibacterial activity is a 'T-cell function dependent on $\mathrm{CD}^{+}{ }^{+}$and $\mathrm{CD} 8{ }^{+}$cell activity which represents a good index of the host resistance against pathogens, even including M. tuberculosis. ${ }^{36}$ This activity was depressed in both groups of patients at time 0 , but, while it increased in the ALC-treated individuals, it decreased in the subjects receiving placebo only. Several hypotheses can be formulated to explain the immunomodulating activities of ALC: (1) ALC may act by supplementation of energy to lymphocytes via ATP; (2) chemotherapy may impair lymphocytic functions in these patients ${ }^{37,38}$ and ALC eventually potentiates the reduced antibacterial activity and/or prevents iatrogenic immunosuppression; or (3) AI.C can modulate the hypothalamus-pituitary adrenal axis with release of enhancing neurohormones and neuropeptides. ${ }^{39}$

As far as determination of serum levels of ${ }^{\mathrm{TNF}} \alpha$ is concerned, no differences were seen between the two groups, since mean values of this CK fluctuated within normal ranges before and after treatment. However, in three cases within the ALC-treated group and in two cases within the placebo group TNF $\alpha$ levels increased by day 30. Although anamnesis, clinical examination, disease and state and other related blood parameters were taken into consideration, a reasonable explanation for under standing the above finding was not achieved. It is noteworthy that this present data confirms that reported by Rook et al., ${ }^{19}$ who also found normal serum levels of $\mathrm{TNF} \alpha$ in TBC patients. In this context, to extend our data further, studies will evaluate in vitro $\mathrm{TNF} \alpha$ release from I.AMstimulated monocytes in ALC-treated 'TBC patients. In fact, detection of TNF $\alpha$ in serum can be prevented by the presence of inhibitors found in TBC and sarcoidosis. ${ }^{40}$

\section{Therapeutic Application of Acetyl-L-carnitine in Mycobacteriosis}

Tuberculosis and leprosy are the two major mycobacterial infections in which a deficit of $\mathrm{Th}$ cells has been recognized, mostly in terms of release of protective CKs, such as II-2 and IFN $-\gamma{ }^{1}{ }^{3,12,13,41} 4.3 \mathrm{On}$ the other hand, according to Grau et al. ${ }^{44} \mathrm{TNF} \alpha$ may cause both protection and clinical manifestations in mycobacterial disease and pathology should be interpreted as the consequence of the protective mechanism. Therefore, a pharmacological modulation of the immune response in mycobacteriosis should be applied to the T-cell compartment, excluding the monocyte-macro- phage system whose products, e.g. II,-1 and TNF $\alpha$, are more detrimental than beneficial. ${ }^{24,44}$

The authors' data indicate that ALC may represent a suitable BRM for treating mycobacteriosis, since it increases T-cell dependent antibacterial activity without effect on in vivo TNF $\alpha$ production in the affected patients. In this respect, the improvement of clinical and immunological findings observed in ALC-treated AIDS patients ${ }^{33}$ indirectly confirms that this compound acts on lymphocytes but not on cellular sources of 'TNF $\alpha$. In fact, several papers support the prominent role of TNF $\alpha$ as the cofactor in the triggering and worsening of HIV infection. ${ }^{45} 48$

Finally, even if these preliminary results seem to support the immunomodulating capacities of AIC, long-term studies and monitoring of additional immune parameters are needed on a broader sample of the population affected by mycobacterial disease.

\section{References}

1. 1)aniel TM, ()xtoby MJ, Pinto li, et al. 'The immunc spectrum in patient with pulmonary tuberculosis. $1 \mathrm{~m}$ Rev Respir Dis 1981; 123: 556569.

2. Dannenberg AM. Immune mechanisms in the pathogenesis of pulmonary tubcrculosis. Rev Infect Dis 1989; 11 (Suppl): S369 S378.

3. Jirillo E, Munno I, 'I'ortorella C, et al. 'T'he immune response to mycobacterial infection. Med S $S_{c i}$ Res 1989; 17: 929931

4. Fillner JJ, Spagnuolo PJ, Schacter B\%. Augmentation of selective monocyte functions in tuberculosis. J Infect Dis 1981; 144: 391397

5. Lamb JR, lathigra R, Rothbard JB, et al. Identification of mycobacterial antigens recognized by 'I' lymphocytes. Rev Infect Dis 1989; 11 (Suppl): $\$ 443$ S447.

6. Munk MLi, Schocl B, Modrow, S, et al. 'I' lymphocytes from healthy individuals with specificity to self-epitopes shared by the mycobactcrial and human 65-kilodalton heat shock protein. I Immunol 1989; 143: 2844 2849.

7. Kabclity D, Bender $\Lambda$, Schondelmaier $S$, et al. $\Lambda$ large fraction of human peripheral blood $\gamma / \delta^{+1} \mathrm{I}^{\prime}$-cells is activated by Mycobacterium tuberculosis but not by tts 65-kDa heat shock protein. J lixp Med 1990; 171: 667 669.

8. O'Brien RI, Happ MP, Dallas $\Lambda$, et al. Stimulation of a major subset of lymphocyte-expressing ' $\mathrm{I}$ '-cell receptor $\gamma \delta$ by an antigen derived from Mycobacterium tuberculosis. Cell 1989; 57: 667674.

9. (Orme IM, Miller IS, Roberts AD, et al. 'I'-lymphocytes mediating protection and cellular cytolysis during the couse of Mycobacterium tuberculosis infection. lividence for different kinetics and recognition of a wide spectrum of protein antigens. I Immunol 1992; 148: 189196.

10. Leveton C. Barnass S, Champion B, et al. 'I'-cell mediated protection of mice against virulent Mycobacterium tuberculosis. Infect Immun 1989; 57: 390395

11. Boom WH, Wallis RS, Chevernak KA. Iuman Mycobacterium tuberculosis reactive (D) ${ }^{+} \mathrm{T}$-cell clones; heterogeneity in antigen recognition, cytokine production, and cytotoxicity for mononuclcar phagocytes. Infect Immun 1991 59. 27372743

12. 'I'oossi R, Kleinhenz. M, Iillner JJ. Defective interleukin-2 production and responsiveness in human pulmonary tuberculosis. J lixp Med 1986; 163 11621172.

13. Onwubalili JK, Scott ( $M$ M, Robinson JA. Deficient immune interferon production in tuberculosis. (Clin Ixp Immunol 1985; 59: 405410.

14. Kunkel SI, Chensuc SW, Strciter RM, et al. Cellular and molecular aspects of granulomatous inflammation. Am J Respir Cell Mol Biol 1988; 1: 439 - 447.

15. Morenco C, 'Taverne J, Mehlert $\Lambda$, et al. lipoarabinomannan from Mycobacterium tuberculosis induces the production of tumour necrosis factor from human and murine macrophages. C.lin I:xp Immunol 1989; 76: 240-245.

16. Barnes PF, Chatterjee D, Abrams JS, et al. Cytokine production induced by Mycobacterium tuberculosis lipoarabinomannan. Relationship to chemical structure. J Immunol 1992; 149: 541547.

17. Fong $\mathrm{Y}, \mathrm{l}$.owry $\mathrm{Sl}$. Tumour necrosis factor in the pathophysiology of infection and sepsis. (lin Immunol Immunopathol 1990; 55: 157162.

18. Iilley $1: \Lambda$, Rook $G \wedge W$. liffect of mycobacteria on sensitivity to the cytotoxic effects of tumour necrosis factor. Infect Immun 1991; 59: 25672572.

19. Rook ( $\mathrm{A}$ W, $\Lambda$ ttiyah $\mathrm{R} \Lambda$, Foley $\mathrm{N}$. 'l'he role of cytokines in the immunopathology of tuberculosis and the regulation of agalactosyl $\operatorname{IgC}$. I.ymphokine Res 1989; 8: 323328

20. Barnes PF, Fong SJ, Brennan PJ, et al. Local production of tumour necrosis factor and II $\mathrm{N}-\gamma$ in tuberculous pleuritis. I Immunol 1990; 145: 149154

21. 'l'akashima 'I', Ueta C, 'T'suyuguchi I, et al. Production of tumour necrosis factor alpha by monocytes from patients with pulmonary tuberculosis. Infect Immun 1990); 58: $3286 \quad 3292$ 
22. Kleinhenz ML, Ellner JJ, Spagnuolo P, et al. Suppression of lymphocytc responses by tuberculous plasma and mycobacterial arabinogalactan: monocyte dependence and indomethacin reversibility. J Clin Invest 1981; 68 $153-162$

23. Ellner JJ, Wallis RS. Immunologic aspects of mycobacterial infections. Rev Infect Dis 1989; 2 (Suppl 2): S455 S459.

24. Fujiwara H, Kleinhenz ME, Wallis $\mathrm{R}$, et al. Increased interlcukin-1 production and monocyte suppressor cell activity associated with human tuberculosis. Am Rev Respir Dis 1986; 133: 7377.

25. Wadee $\Lambda \mathrm{A}$, Clara AM. A 25-kilodalton fraction from Mycobacterium tuberculosis that inhibits hexose monophosphate shunt activity, lyso\%yme release, and $\mathrm{H}_{2} \mathrm{O}_{2}$ production: reversal by gamma interferon. Infect Immun 1989; 57: 864869

26. Antonaci S, Jirillo Is, Polignano $\Lambda$, et al. livaluation of phagocyte functions, inflammatory lymphokine activities and in vitro antibody synthesis in patıents with active and chronic pulmonary tuberculosis. Cytobios 1991; 67: 135144.

27. Radin RC, 'Zeiss CR, Phair JP. Antibodies to purified protein derivative in different immunoglobulins classes in the diagnosis of tuberculosis in man. Int Arch Allergy Appl Immunol 1983; 70: 25 29.

28. Daniel TM, Debanne SM. The serodiagnosis of tubcrculosis and othe mycobacterial diseases by enzyme-linked immunosorbent assay. $1 \mathrm{~m}$ Rev Respir 1)is 1987; 135: 1137-1151.

29. Antonaci $S$, 'Iortorella $C$, Jirillo I: Immunomodulating properties of thymic hormones in immunocompromised host. Med Sii Res 1991; 19: 539541.

30. Bremer J. Carnitine. Metabolism and functions. Physiol Rev 1983; 63 14201480 .

31. Foresta P, Albertoni C, Ramacci M'T et al. Immunological parameters in aged rats: effects of acetyl-1,-carnitine. In: De Simone $C$, Martelli $1: \Lambda$, eds. Stress, immunity and ageing. A role for acetyl-I-carnitine. Amsterdam: lilsevicr Science Publishers B.V. (Biomedical Division), 1989; 97107.

32. Monti $\mathrm{D}$, Cossarizza $\Lambda$, 'Troiano $\mathrm{I}$, et al. Immunomodulatory properties of 1.-acetyl-carnitine on lymphocytes from young and old humans. In: De Simone C, Martelli $\mathbf{E} \Lambda$, eds. Stress, immunity and ageing. 1 role for acetyl-I-carnitine. Amsterdam: Elsevier Science Publishers B.V. (Biomedical Division), $1989 ; 183 \cdot 196$

33. De Simone C, Calvani M, Catania S, et al. Acetyl-1-carnitine as a modulator of the neuroendocrine-immune interaction in $\mathrm{HIV}^{\prime}$ subjects. In: De Simone C, Martelli $\mathrm{I} \Lambda$, cds. Stress, immunity and ageing. 1 role for acetyl-I.-carnitine Amsterdam: lilsevier Science Publishers B.V. (Biomedical Division), 1989) 125138.

34. De Simone C, 'Tzantzoglou S, Jirillo E, et al. I-Carnitine deficiency in AIDS patients. AIIDS 1992; 6: 203205.

35. Jirillo Li, $A$ tamura $M$, Munno I, et al. liffects of acetyl-1-carnitine oral

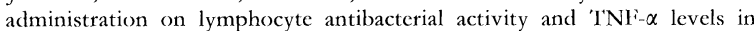
patients with active pulmonary tuberculosis. $\Lambda$ randomized double blind versus placebo study. Immunopbarmacol Immunotoxicol 1991; 13: 135146.

36. Antonaci S, Tortorella C, De Simone C, et al. Role of bacteria lipopolysaccharides in the development of natural antibacterial activity mediated by human peripheral blood ' $T$ ' lymphocytes. Intern Rev Immunol 1990; 6: $237 \cdot 245$
37. Villa MI, Rappocciolo G, Piazza P, et al. 'The interference of antibodies with antigen specific antibody response in man. Int I Immunopharmacol 1986; 8 805809 .

38. Youmans AS, Youmans (GP. Eiffect of metabolic inhibitors on the formation of antibody to sheep erythrocytes, on the development of delayed hypersensitivity, and on immune response to infection with Mycobacterium tuberculosis in mice. Infect Immun 1978; 19: 211. 216.

39. Butler I.D, Layman NK, Riedl PI:, et al. Neuroendocrine regulation of in vivo cytokine production and effects: I. In vivo regulatory networks involving the ncuroendocrine system, interleukin-1 and tumour necrosis factor-alpha. J Neuroimmunol 1989; 24: 143153.

40. Foley N, I ambert C, McNicol M, et al. An inhibitor of the toxicity of tumour necrosis factor in patients with sarcoidosis, tuberculosis and Crohn's disease. Clin lixp Immunol 1990; 80: 395399.

41. Nogueira N, Kaplan (3, J evy I, et al. Defective gamma-interferon production in leprosy. Reversal with antigen and interleukin-2. J Jixp Med 1983; 158: 2165 2170

42. Mohaghegpour N, Gelbe R, Iarrick JW et al. Defective cell-mediatec immunity in leprosy: failure of ' $\mathrm{I}$-cells from lepromatous leprosy patients to respond to Mycobacterium leprae is associated with expression of interleukin-2 receptor and is not reconstituted by interleukin-2. I Immunol 1985; 135: 1443-1449.

43. Munno I, Pellegrino NM, Fumo ( 3 , et al. Studies on lymphokine production in lepromatous leprosy patients. (ytobios 1990; 62: 141147.

44. Grau GE, Parida SK, Pointaire P, et al. 'I'NT' and mycobacteria. In: Beutle $\mathrm{B}$, ed. Tumour necrosis factor: the molecules and their emerging role in medicine. $\mathrm{New}$ York: Raven Press, 1992; 329340.

45. Jirillo 1:, Greco B, Munno I, et al. Demonstration of an exaggerated serum release of tumour necrosis factor alpha and interleukin- $1 \beta$ in HIV-infected patients: a possible correlation with circulating levels of bacterial lipopolysaccharides. In: Nowotny $\Lambda$, Spitzer JJ, Ziegler EJ, eds. Cellular and molecular aspects of endotoxin reaction. Amsterdam: Hlsevier Science Publishers (Biomedical Division), 1990: 529535.

46. Matsuyama 'T, Kobayashi N, Yamamoto N. Cytokines and HIV infection: is AIDS a tumour necrosis factor disease? AII)S 1991; 5: 14051417

47. Dezube BJ, Pardce $\Lambda \mathrm{B}$, Beckett $\mathrm{l} \Lambda$, et al. Cytokine dysregulation in $\Lambda \mathrm{II} S$ in vivo overexpression of $\mathrm{mRN} \Lambda$ tumour necrosis factor- $\alpha$ and its correlation with that of the inflammatory cytokine (GRO. J Acq Immune Defic Syndrom 1992; 5: 10991104

48. Mastroianni CM, Paoletti I', Valenti C, et al. 'T'umour necrosis factor ('I'NI' $\alpha$ ) and neurological disorders in HIV infection. J Neurol Neurosurg P'sychiat 1992 55: 219. 221 .

ACKNOWILEDGEMLNT'S. This paper was supported in part by grants from M.U.R.S.I. (40\% and $60 \%)$, Rome, Italy. 


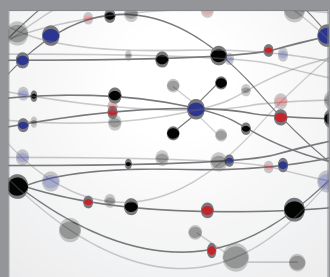

The Scientific World Journal
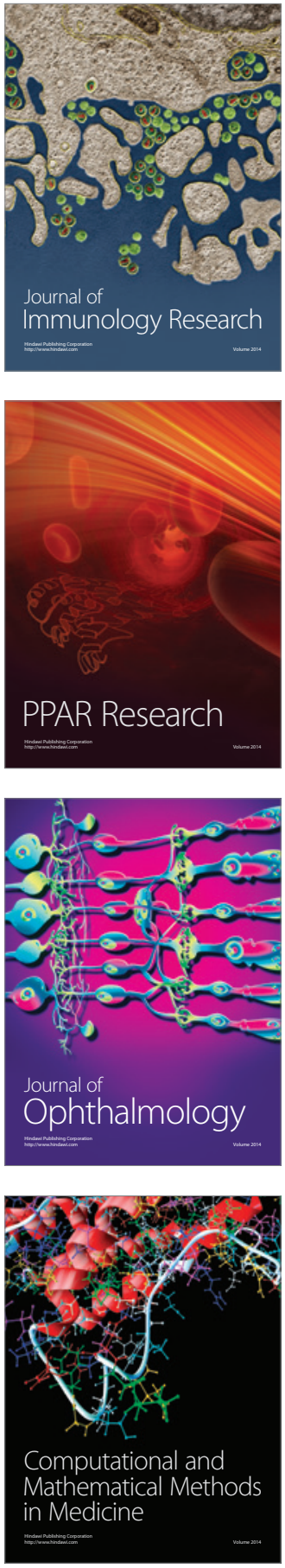

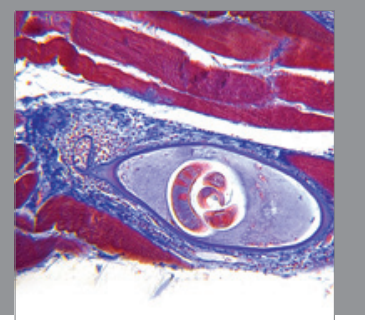

Gastroenterology

Research and Practice
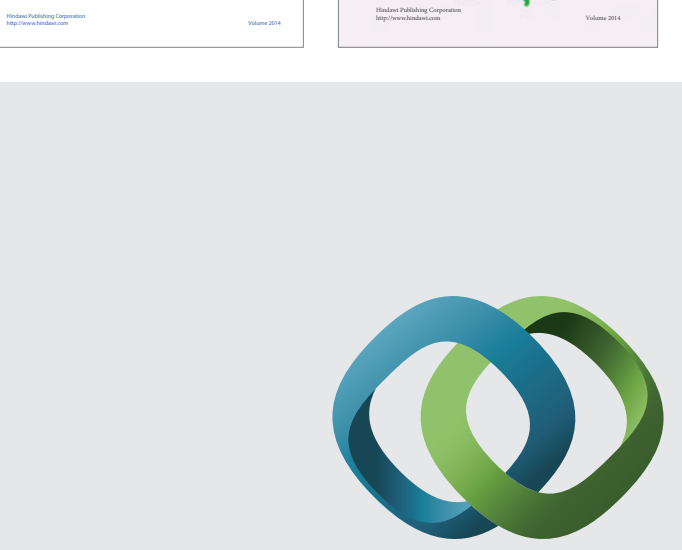

\section{Hindawi}

Submit your manuscripts at

http://www.hindawi.com
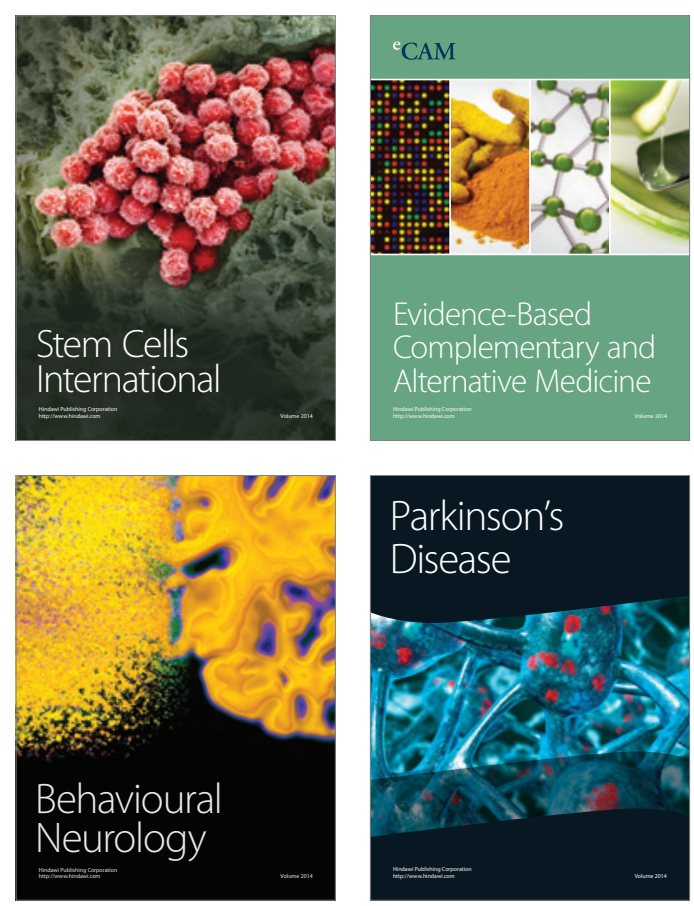

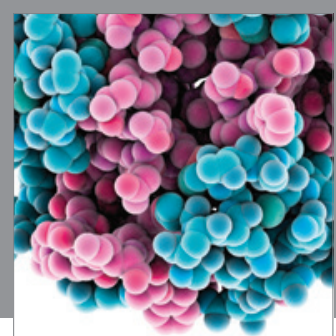

Journal of
Diabetes Research

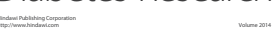

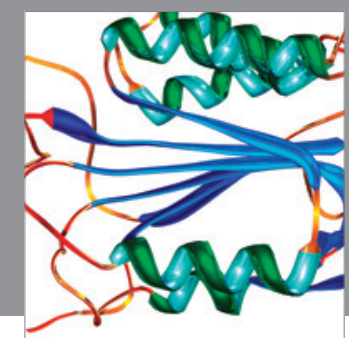

Disease Markers
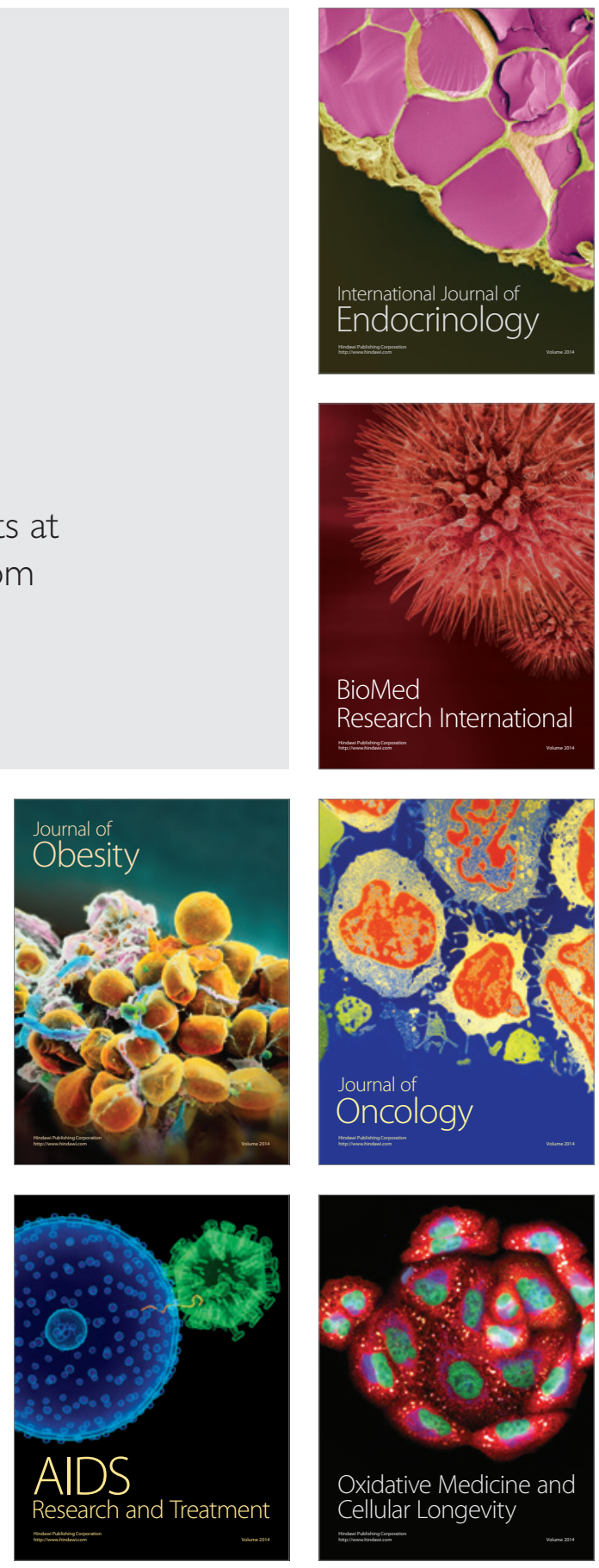